Brain, Behavior and Evolution
Received: October 19, 2007

Returned for revision: December 21, 2007 Accepted after revision: January 11, 2008

Published online: April 21, 2008

\title{
Developmental and Regional Patterns of GAP-43 Immunoreactivity in a Metamorphosing Brain
}

\author{
Andrea Megela Simmons ${ }^{a, b}$ Leslie H. Tanyu ${ }^{a}$ Seth S. Horowitz ${ }^{a, b}$ \\ Judith A. Chapman a Rebecca A. Brown ${ }^{a}$ \\ Departments of a Psychology and ${ }^{\mathrm{b}}$ Neuroscience, Brown University, Providence, R.I., USA
}

\section{Key Words}

Growth-associated protein $43 \cdot$ Plasticity - Metamorphosis . Bullfrog $\cdot$ Midbrain $\cdot$ Forebrain $\cdot$ Cranial nerves

\footnotetext{
Abstract

Growth-associated protein-43 is typically expressed at high levels in the nervous system during development. In adult animals, its expression is lower, but still observable in brain areas showing structural or functional plasticity. We examined patterns of GAP-43 immunoreactivity in the brain of the bullfrog, an animal whose nervous system undergoes con-
}

siderable reorganization across metamorphic development and retains a strong capacity for plasticity in adulthood. Immunolabeling was mostly diffuse in hatchling tadpoles, but became progressively more discrete as larval development proceeded. In many brain areas, intensity of immunolabel peaked at metamorphic climax, the time of final transition from aquatic to semi-terrestrial life. Changes in intensity of GAP-43 expression in the medial vestibular nucleus, superior olivary nucleus, and torus semicircularis appeared correlated with stage-dependent functional changes in processing auditory stimuli. Immunolabeling in the Purkinje cell layer of the cerebellum and in the cerebellar nucleus was detectable

\begin{tabular}{|c|c|c|c|}
\hline \multicolumn{4}{|c|}{ Abbreviations used in this paper } \\
\hline $\mathrm{DMN}$ & dorsal medullary nucleus & nVIII & eighth cranial nerve (auditory/vestibular) \\
\hline $\mathrm{Cb}$ & cerebellum & $\mathrm{nI}$ & first cranial nerve (olfactory) \\
\hline $\mathrm{Cb}$ nucleus & cerebellar nucleus & nII & second cranial nerve (optic) \\
\hline \multirow[t]{2}{*}{$\mathrm{HT}$} & dorsal and ventral hypothalamus, caudal to & OT & optic tectum \\
\hline & the preoptic area & $\mathrm{OV}$ & optic ventricle \\
\hline III & third ventricle & Para & paragigantal nucleus \\
\hline IV & fourth ventricle & SON & superior olivary nucleus \\
\hline Lat & lateral ventricle & Teg & tegmentum \\
\hline LLnp & lateral line neuropil & TS & torus semicircularis \\
\hline \multirow[t]{2}{*}{ Medial thalamic n } & anterior, central, posterior, ventromedial & TSl & laminar nucleus of the torus semicircularis \\
\hline & thalamus & Telencephalon & medial septum, ventral striatum, \\
\hline MVN & medial vestibular nucleus & & ventricular zone \\
\hline
\end{tabular}

\section{KARGER}

\section{(C) 2008 S. Karger AG, Base}

Fax +4161306 1234 E-Mail karger@karger.ch www.karger.com www.karger.com/bbe
A.M. Simmons

Department of Psychology, Box 1853, Brown University

Providence, RI 02912 (USA)

Tel. +1 401863 2283, Fax +1 4018631300

E-Mail Andrea_Simmons@brown.edu 
at most developmental time points. Heavy immunolabel was present from early larval stages through the end of climax in the thalamus (ventromedial, anterior, posterior, central nuclei). Immunolabel in the tadpole telencephalon was observed around the lateral ventricles, and in the medial septum and ventral striatum. In postmetamorphic animals, immunoreactivity was confined mainly to the ventricular zones and immediately adjacent cell layers. GAP-43 expression was present in olfactory, auditory and optic cranial nerves throughout larval and postmetamorphic life. The continued expression of GAP-43 in brain nuclei and in cranial nerves throughout development and into adulthood reflects the high regenerative potential of the bullfrog's central nervous system.

Copyright $\odot 2008$ S. Karger AG, Basel

\section{Introduction}

Many species of anuran amphibians undergo a developmental process called metamorphosis, during which an aquatic limbless tadpole transforms into an amphibious quadrupedal frog. Metamorphosis as a process comprises periods of progressive transformations in external body morphology, in internal organs, and in the neuroanatomical organization of the brain [Shi, 1999]. All sensory systems undergo considerable reorganization over metamorphic development. In the visual system, for example, ipsilateral projections from the retina to the optic tectum and to the thalamus fully develop later in larval life than do contralateral projections, which are present at the earliest postembryonic stages [Currie and Cowan, 1975; Hoskins, 1986]. In all but permanently aquatic species such as the African clawed frog, Xenopus laevis, the lateral line system degenerates during metamorphic climax [Fritzsch et al., 1984]. The two auditory peripheral transduction pathways develop and mature at different time courses over larval life, and these peripheral changes are paralleled by functional and connectivity changes in central auditory and vestibular nuclei [BoatrightHorowitz and Simmons, 1997; Horowitz et al., 2007a; Simmons and Horowitz, 2007]. The extent and rapidity of the anatomical, physiological and morphological changes occurring during metamorphosis, particularly during metamorphic climax when the animal finally loses larval characteristics and exhibits adult structures, make this phenomenon a fundamental model for the study of naturally occurring brain plasticity correlated with changes in environmental demands.
The molecular substrates facilitating and accompanying metamorphosis in anurans are of great interest in understanding processes of development and plasticity. A great deal of research has been focused on molecular cues mediating development during embryonic stages, particularly in Xenopus [Shi, 1999]. Aside from the extensive research into the mediation of metamorphosis by thyroid hormone and its receptors [Denver, 1998], relatively less attention has been paid to identifying molecular triggers and supporters of transformation during the lengthier larval stages in any anuran species. One protein known to be closely associated with axonal outgrowth and synaptogenesis in vertebrates is the intracellular phosphoprotein growth-associated protein GAP-43 (also known as B-50, F1, neuromodulin, pp46) [Jacobson et al., 1986; Meiri et al., 1986; Skene, 1989; Benowitz and Routtenberg, 1997; Oestreicher et al., 1997]. In many different vertebrate species, including anurans, the expression of this protein in particular areas of the brain is high during development [Jacobson et al., 1986; McGuire et al., 1988; Dani et al., 1991; Golding and Tonge, 1993; Horváth et al., 1997; Schrama et al., 1997]. Expression is typically downregulated in the adult, but in mammals is still observed in brain areas such as the frontal cortex and hippocampus, regions associated with continuous synaptic plasticity [Benowitz et al., 1988, 1990; McGuire et al., 1988; Neve et al., 1988]. Moreover, in anurans, reptiles, and mammals, expression of GAP-43 in adults is upregulated in some brain areas after injury [Skene and Willard, 1981; Benowitz and Lewis, 1983; van der Zee et al., 1989; Golding and Tonge, 1993; Illing et al., 1999; Chaisuksunt et al., 2000; Rodger et al., 2001; Soto et al., 2003]. These features of GAP-43 make it an interesting candidate model for deciphering the molecular triggers of metamorphosis.

Previous immunohistochemical work in two ranid species [Rana temporaria and $R$. pipiens; Golding and Tonge, 1993] showed that GAP-43 is widespread throughout the brain and spinal cord of tadpoles at some stages of development, with particularly heavy concentration in the cerebellum, optic tectum, diencephalon and telencephalon. This work was restricted to only a limited time span of larval development, however, and did not include the crucial stages of metamorphic climax, where expression might be expected to be up-regulated in tandem with the considerable structural and functional changes occurring in the brain during this period. GAP-43 expression in developing Xenopus has been examined in selected cranial nerve and fiber tracts only during embryonic and very early larval stages [Schrama et al., 1997], but again not during metamorphic climax. 
In this study, we examine the immunohistochemical distribution of GAP- 43 in the American bullfrog, $R$. catesbeiana, across the developmental span from the earliest postembryonic stages, through metamorphic climax, and into adulthood. The nervous system of the bullfrog undergoes more dramatic changes over development than those seen in Xenopus, particularly in auditory/vestibular pathways, and thus we might expect dramatic changes in GAP-43 expression, as indexed by changes in intensity and distribution of immunolabeling, during bullfrog metamorphosis. We hypothesized that changes in expression in the auditory medulla and midbrain, areas which we have previously shown to undergo considerable anatomical and physiological changes over development [Boatright-Horowitz and Simmons, 1997; Chapman et al., 2006; Simmons et al., 2006; Horowitz et al., 2007a, b], would correlate with patterns of GAP-43 immunoreactivity. Further, we examined patterns of GAP43 immunoreactivity in selected cranial nerves and in the forebrain, to determine if any changes in expression reflect a general process of growth and reorganization affecting the entire brain simultaneously, or if certain patterns of expression are temporally or spatially specific. We also hypothesized that expression of GAP- 43 protein would peak during metamorphic climax, paralleling the considerable widespread reorganization of the entire nervous system that occurs during this time of final transition from aquatic to semi-terrestrial life.

\section{Materials and Methods}

\section{Animals}

Rana catesbeiana $(\mathrm{n}=49)$ were obtained from a commercial supplier (Dozier Lester, Duson, La., USA). Tadpoles were staged according to the Gosner [1960] criteria and then classified into developmental groups as described by McDiarmid and Altig [1999]. These categories are: hatchlings (stages 21-25, the earliest freely-living postembryonic animals, $\mathrm{n}=3$ ); early larval stages (stages 26-30, with undifferentiated hindlimb buds and no external forelimbs, $\mathrm{n}=10$ ); late larval stages (stages 31-41, progressive differentiation of hindlimbs and internal forelimb development, $n=14$ ); a subset of this group comprising stages 38-41 are functionally classified as deaf period as defined by Boatright-Horowitz and Simmons [1997]; and metamorphic climax (stages 42 46 , showing fully-developed hindlimbs and progressive forelimb development, from initial external emergence to full development, $n=7)$. Postmetamorphic animals $(n=15)$ included froglets (snout-vent lengths $<5.5 \mathrm{~cm}, 1-90$ days after completion of cli$\max , \mathrm{n}=3$ ), subadults (snout-vent lengths between 5.5 and $10 \mathrm{~cm}$, $\mathrm{n}=4$ ), and adults (snout-vent lengths $>10 \mathrm{~cm}, \mathrm{n}=8$ ).

Tadpoles were group-housed in plastic aquaria containing dechlorinated aerated water and were fed cooked unsalted spinach ad libitum. Postmetamorphic animals were housed individually in plastic terraria containing soil and water and were fed live crickets ad libitum. The colony room was maintained at $25-28^{\circ} \mathrm{C}$ on a 12/12 light/dark cycle. All animal procedures were approved by the Brown University Institutional Animal Care and Use Committee and are consistent with federal regulations.

\section{Western Blot}

We performed Western blot analysis to confirm that the commercially available antibody (generated in mouse) that we used in these experiments had similar specificity for anuran GAP-43. Animals ( $\mathrm{n}=16 ; 14$ tadpoles, 2 postmetamorphic animals) were terminally anesthetized in $0.6 \%$ (weight per volume, $\mathrm{w} / \mathrm{v}$ ) tricaine methanesulfonate (MS-222, pH 7.0; Sigma, St Louis Mo., USA) for 10-20 min. The brains (obex through mid-telencephalon) were removed on ice and stored at $-80^{\circ} \mathrm{C}$. At the time of the experiment, brains were homogenized in 20 volumes of $20 \mathrm{mM}$ Tris ( $\mathrm{pH}$ 7.4; Sigma) and centrifuged at 13,500 $\mathrm{g}$ for $10 \mathrm{~min}$. Laemmli buffer ( $2 \times$; Sigma S3401) was added to the tissue and the samples were then boiled for $5 \mathrm{~min}$. Proteins were separated by sodium dodecyl sulfate polyacrylamide gel electrophoresis ( 8 or $10 \%$ polyacrylamide precast gels; ISC Bioexpress, Kaysville UT, or BioRad Laboratories, Hercules, Calif., USA). A prestained molecular weight marker (Sigma C2242), a negative control (saline in loading buffer), and a positive control (rodent brain homogenate, BD Biosciences catalog \#51-16406N, San Jose, Calif., USA) were electrophoresed on the same gels alongside anuran tissue. Proteins were then electrophoretically transferred onto a nitrocellulose membrane (BioRad semi-dry transblotter system, BioRad Laboratories). GAP-43 protein was detected by membrane incubation (overnight, $4^{\circ} \mathrm{C}$ ) with mouse monoclonal anti-GAP-43 (1:2,500, Sigma G9264). This antibody recognizes both phosphorylated and dephosphorylated forms of GAP-43. Phosphorylated GAP-43 is at high levels in motile growth cones [Dent and Meiri, 1998]. The membranes were then incubated in goat anti-mouse peroxidase conjugate (1:750, Sigma A4416; $1 \mathrm{~h}$ at room temperature). The signal was developed using Vector VIP or 3,3'-diaminobenzidine (DAB) Substrate Kits (both from Vector Laboratories, Burlingame, Calif., USA). All experiments were performed using the same parameters under standard conditions, and the same tissue was run on separate gels or in multiple lanes on the same gel to confirm results. The membranes were digitally scanned and the scans imported into Corel Photo Paint v. 11 (Corel Corp, Ont., Canada) for preparation of illustrations.

Immunohistochemistry

Animals ( $\mathrm{n}=33$; 20 tadpoles, 13 postmetamorphic animals) were deeply anesthetized by submersion in $0.6 \%$ MS-222, and transcardially perfused with heparinized $0.9 \%(\mathrm{w} / \mathrm{v})$ saline followed by $4 \%$ (w/v) paraformaldehyde ( $\mathrm{pH} 7.4)$. Brains were immediately removed and postfixed in $4 \%$ paraformaldehyde for $12-24 \mathrm{~h}$ at $4{ }^{\circ} \mathrm{C}$. After being stripped of overlying membranes, the brains were embedded in $5 \%(\mathrm{w} / \mathrm{v})$ agarose (ISC Bioexpress) in saline, and sliced, from the obex to the mid-telencephalon, using a calibrated 1000 Plus vibratome (Vibratome, St. Louis Mo., USA), either in the coronal plane (50 $\mu \mathrm{m}$ thickness, $\mathrm{n}=28)$ or in the sagittal plane ( $75 \mu \mathrm{m}$ thickness, $\mathrm{n}=5)$. Sections were collected on consecutive gelatin-coated glass slides to create different slide sets for processing. Sections were pre-incubated in Tris-buffered saline $\{$ TBS; $0.1 \%(\mathrm{v} / \mathrm{v})$ Triton X-100 (Sigma) and 0.5\% (w/v) bovine serum albumin (Sigma) in $0.1 \mathrm{M} \mathrm{PBS}, \mathrm{pH} 8.0\}$ and $10 \%$ (v/v) nor- 


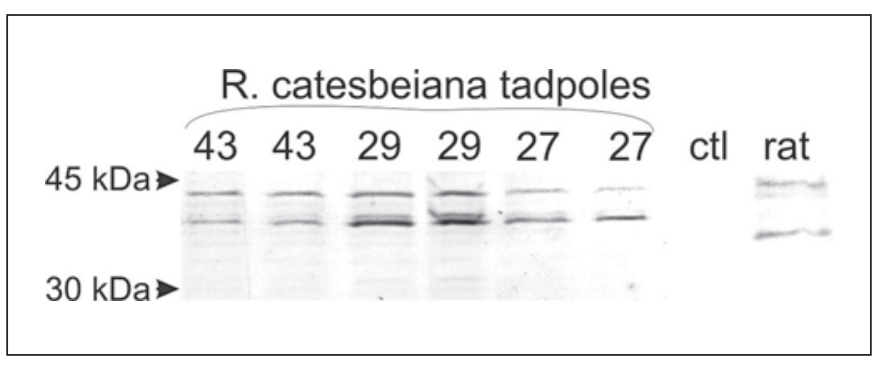

Fig. 1. Western blot shows the primary antibody for GAP-43, developed in mouse, recognizes amphibian GAP-43. This particular example is from one experiment run on a $10 \%$ gel. Molecular weights $(\mathrm{kDa})$ are shown in the first column (left). The lanes, from left to right, show results from tissue from a stage 43 tadpole (2 replications), stage 29 tadpole ( 2 replications), stage 27 tadpole (2 replications), negative control (saline loading buffer) and rat brain lysate (1 replication). The blot was digitally scanned and imported into Corel PhotoPaint for preparation of the illustration, but the resulting image was not digitally manipulated. Background staining is visible in this figure. Variations in intensity of the major bands among animals are likely related to different amounts of protein present in these tissue samples.

mal horse serum (HyClone, Logan UT) for 15 min at room temperature while shaking. They were then incubated in mouse monoclonal anti-GAP-43 (1:2,500, Sigma G9264; $3 \mathrm{~d}$ at $\left.4^{\circ} \mathrm{C}\right)$. Alternate sections were either used for controls (incubation without either the primary or secondary antibodies) or were incubated with other primary antibodies as part of another experiment, not described here. After incubation with the primary antibody, tissue sections were washed in TBS and 10\% normal horse serum for $15 \mathrm{~min}(\times 3$, room temperature), followed by incubation $(24 \mathrm{~h}$ at $4^{\circ} \mathrm{C}$ ) with secondary antibody (either goat anti-mouse AlexaFluor 594 (A11005, 1:750) or Alexa Fluor 488 (A11001, 1:750), both from Invitrogen, Eugene, Oreg., USA). Sections were washed and mounted with non-fluorescent mounting medium (Aquamount, Polysciences, Warrington, Pa., USA). Tissue from larval and early postmetamorphic animals was processed in mixed-stage batches in order to control for any possible variations in experimental procedure or in viability of antibodies. Tissue from adult brains was separately processed as part of an experiment examining cell proliferation after intraperitoneal injection with 5-bromo- 2 '-deoxyuridine [BrdU; Simmons et al., 2008]. For all experiments, care was taken to standardize all procedures for both slicing and staining.

Sections were imaged using a Olympus (Melville, N.Y., USA) BX-60 microscope outfitted with custom fluorescence cubes and a Magnafire (Optronics, Goleta, Calif., USA) CCD camera linked to a Dell Pentium 4 computer using an IEEE-1394 PCI frame grabber (Texas Instruments, Dallas, Tex., USA). Images were taken at similar magnifications (either $10 \times$ or $40 \times$ ) with automatic photographic settings and saved as 24-bit RGB TIFF files. GAP43 fluoresced either red or green, depending on the secondary antibody used, against a yellow-green background. For the preparation of illustrations, images were converted to CMYK or 8-bit grayscale TIFF files using standard settings, and were contrast and brightness enhanced (Corel Photo Paint v. 11), but were not otherwise manipulated.

Anatomical boundaries and terminology are consistent with those described for developing [Simmons and Horowitz, 2007; Horowitz et al., 2007a; Horowitz and Simmons, 2007] and adult [Nieuwenhuys and Opdam, 1976; Opdam et al., 1976; Wilczynski and Northcutt, 1983; Marín et al., 1997] ranid brains. Atlases of the tadpole brain at medullary, mesencephalic, and diencephalic levels have been published previously [Horowitz and Simmons, 2007].

\section{Results}

\section{Western Blot}

Figure 1 shows the results of Western blot analysis to determine the specificity of the GAP-43 antibody used in this study. Data are shown from one membrane containing a positive control lane (rat brain lysate), a negative control lane, and duplicate lanes from tadpoles at 3 different stages. The positive control lane showed one thick discrete band at around $45 \mathrm{kDa}$, with a lighter band at around $38-40 \mathrm{kDa}$. Two discrete bands were also visible in the tadpole tissue, one at around $43 \mathrm{kDa}$ and a second at around $40 \mathrm{kDa}$. There were no consistent, discrete bands present in the blots at other locations, although background levels did vary between membranes.

\section{Immunostaining: General Trends}

Figure 2 shows images of nVIII, near its entry point into the medulla, from one subadult frog, with consecutive sections processed with primary antibody alone (fig. 2A), secondary antibody alone (fig. 2B), and primary and secondary antibody together (fig. 2C). No staining above background was present in the two control sections, but clear immunolabel was observed in the tissue processed using both primary and secondary antibody. These data show that our technique reliably detected GAP-43 immunolabel without false positive results.

The pattern of GAP-43 immunolabel varies in both distribution and intensity across developmental stages. In hatchling and early larval animals, label is primarily evident as diffuse staining of neuropil, particularly in midbrain and forebrain areas. This result is consistent with the diffuse nature of label in early postnatal rat brainstem [Horváth et al., 1997], but the diffuse pattern makes quantification of the absolute amount of label difficult in these developmental stages. Beginning in late larval stages and extending to adult animals, label becomes more discrete and more confined to perikarya or to puncta surrounding unlabeled soma. Label of presumptive cross-cut fibers and 

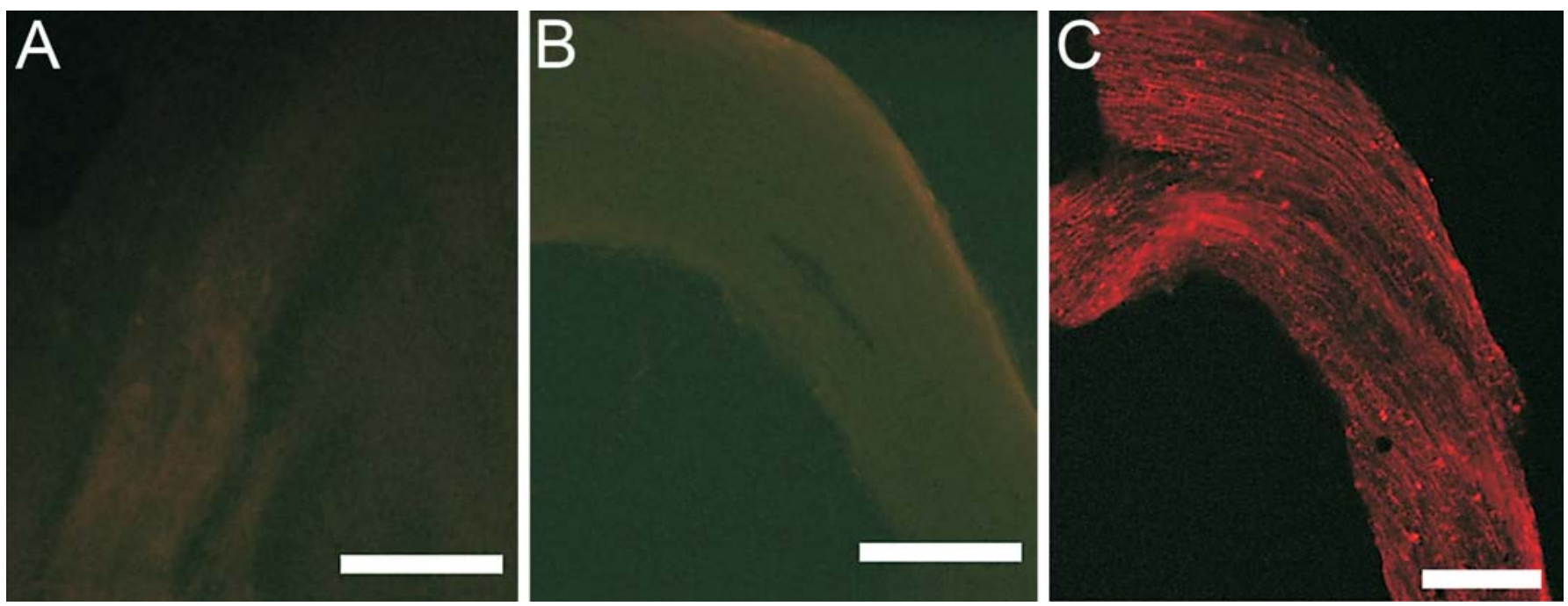

Fig. 2. Control experiments show the specificity of the GAP-43 antibody used in this study. Consecutive slices of nVIII and attached section of the lateral medullary region from a subadult frog incubated with A primary antibody alone, B secondary antibody alone, and $\mathbf{C}$ primary and secondary antibody together. There is only background staining in $\mathbf{A}$ and $\mathbf{B}$, but immunoreactivity (red; color online only) is present in $\mathbf{C}$. In all sections, dorsal is up and medial is to the left. Scale bars $=100 \mu \mathrm{m}$.

Table 1. Qualitative estimates of intensity of GAP-43 label in selected brain regions across development

\begin{tabular}{llllllll}
\hline & $\begin{array}{l}\text { Hatchling } \\
(21-25)\end{array}$ & $\begin{array}{l}\text { Early Larval } \\
(26-30)\end{array}$ & $\begin{array}{l}\text { Late Larval } \\
\left(31-37 ; 38-41^{*}\right)\end{array}$ & $\begin{array}{l}\text { Climax } \\
(42-46)\end{array}$ & Froglet & Subadult & Adult \\
\hline nVIII & +++ & ++ & $+++;++$ & +++ & ++ & $++/+$ & + \\
nI & & & $+++;++$ & + & + & + & + \\
nII & & & $++;++$ & + & + & + & + \\
DMN & 0 & 0 & $+/-;+/-$ & $+/-$ & $+/-$ & 0 & 0 \\
MVN & 0 & 0 & $+/-;+$ & ++ & $+/-$ & 0 & 0 \\
SON & 0 & 0 & $+;+/-$ & ++ & + & $+/-$ & $+/-$ \\
Cerebellum & + & + & $+;+$ & ++ & + & + & + \\
Cb nucleus & $+/$ & + & ++++ & ++ & + & + & + \\
OT & +++ & + & $++;++$ & +++ & + & + & + \\
TSl & +++ & + & $++;++$ & +++ & ++ & + & + \\
Medial thalamic n. & ++ & +++ & $+++;+++$ & +++ & ++ & ++ & ++ \\
HT & ++ & +++ & $+++;++$ & +++ & ++ & + & + \\
Telencephalon & & ++ & $++;++$ & ++ & + & + & + \\
\hline
\end{tabular}

* Stages 38-41 in the late larval group are also categorized as deaf period.

0 = No label; +/- = minimal label; + = light/low label; ++ = moderate label; +++ = heavy label. Empty cell indicates no data for that stage group.

of short segments of fibers is also observed. Moreover, as development proceeds from hatchling to deaf period stages, the extent of label (whether diffuse or more discrete) within a particular brain area tends to become more restricted. This pattern reverses in metamorphic climax stages when immunolabel in most brain nuclei is more widely distributed and often more intense compared to label in earlier stages. Another apparent shift in distribution of label occurs in postmetamorphic animals, where immunoreactivity is mostly confined to the ventricular zones and immediately surrounding cell layers, and to fiber-rich areas such as the dorsal and ventral arcuate tracts, 
the lateral lemniscus, the optic tract, and the accessory olfactory tract. Table 1 shows results of qualitative evaluation of the intensity of label in selected brain areas. Three of the authors separately rated the relative intensity of label within the listed brain areas on a five point scale $(0=$ no label; +++ = heavy label), with ratings from two observers made on coded images. Ratings from the three observers were highly consistent, and entries in the table represent the most common rating for all sections from that specific brain area from all animals in that particular developmental group. Variability in ratings was due predominantly to two factors - individual variability in patterns of immunolabeling between animals within a particular stage group, and the diffuseness of label in hatchling and early larval animals. This latter factor makes quantification unreliable, and difficult to compare with that of stages in which label was more discrete. Data for the medially-located thalamic nuclei (anterior, central, ventromedial, posterior nuclei; there was little to no label in lateral areas of the thalamus) and for telencephalic nuclei (medial septum and ventral striatum, the areas where labeled cell bodies and puncta outside the ventricular zone were most likely to be observed) are combined to provide one rating each (rather than multiple ratings for each nucleus in these brain areas), because there were no consistent qualitative differences between individual nuclei in these areas. Developmental changes in the diffuseness of label within a particular brain area (whether staining of individual cells or fibers could be reliably detected) are noted in the text.

\section{Cranial Nerves}

Heavy fluorescent label of GAP- 43 is observed in nVIII in hatchlings (fig. $3 \mathrm{~A}$, stage 23), late larval tadpoles (fig. 3B, stage 34), and metamorphic climax tadpoles (fig. 3C, stage 45). In these cases, a majority of individual fibers within the nerve appears to be labeled. Moderate label is typically observed in early larval animals and in froglets (table 1). Label is generally moderate to light in subadults (fig. 2C) and light in adults (fig. 3D), and visible in only a subset of individual fibers within the nerve. GAP-43 immunolabel is also present in both the olfactory (nI; fig. 3E-H) and optic (nII; fig. 3I-L) nerves at all stages of development. In $\mathrm{nI}$, label is heavy in late larval stages (fig. 3E, stage 31; no data are available for hatchling and early larval animals), with a qualitative decline to moderate label in deaf period animals (fig. 3F, stage 38), and to light label in metamorphic climax (fig. 3G, stage 42) through the postmetamorphic period (fig. $3 \mathrm{H}$, subadult). GAP-43 expression in $\mathrm{nII}$ is moderate in late larval (fig. 3I, stage 31) and deaf period (fig. 3J, stage 38) animals, and is light during metamorphic climax (fig. $3 \mathrm{~K}$, stage 42) and older animals (fig. 3L, subadult). During larval stages, strong GAP-43 label is also seen in other cranial nerves, most particularly nV, nVI, and nIX (data not shown).

\section{Brainstem}

There is no or only minimal expression of GAP-43 in the region of the dorsal medullary nucleus (DMN; anuran analog to the mammalian cochlear nucleus and a direct target of nVIII fibers) or in the lateral line neuropil (LLnp) at any developmental stage (fig. 4A, stage 27). Light label that probably represents staining of fibers cross-cut in the coronal plane is often observed at or near the entry point of nVIII and along the dorsal margin of the medulla but outside the boundaries of the DMN (data not shown). There is no or only minimal immunolabel for GAP-43 in the area of the medial vestibular nucleus (MVN, another direct target of nVIII fibers in tadpoles) from hatchling (fig. 4A, stage 27) through late larval stages. At metamorphic climax, light to moderate label of perikarya and of puncta surrounding unlabeled cell bodies is visible in this nucleus (fig. $4 \mathrm{~B}$, stage 45 ). This label is primarily restricted to puncta surrounding unlabeled cell bodies. Beginning in the late larval period and extending through metamorphic climax, there is light to moderate label of puncta and/or perikarya in the medial reticular gray (fig $4 \mathrm{C}$, stage 36 ), most particularly in and directly adjacent to the ventricular zone and in nucleus $\mathrm{nVI}$; short segments of fibers in the dorsal arcuate tract also show label (fig. 4C). This pattern of label persists at lower intensity and with more restricted distribution in postmetamorphic animals. Immunolabeling for GAP-43 in the superior olivary nucleus (SON) is minimal or absent during hatchling and early larval stages, and increases to a light to moderate level during late larval stages (fig. 4C, stage 36). Label of neuropil is light and diffuse during the deaf period, but becomes more discrete and of moderate intensity during metamorphic climax, where both label of puncta and of perikarya is visible (fig. 4D, stage 45). There is minimal to light label of the SON in froglets, and minimal and no label in subadults and adults, respectively. Beginning in late larval stages and extending into adult stages, light label in short fiber segments of the ventral arcuate and spinal lemniscus tracts is present (data not shown).

In the cerebellum, there is light to moderate cell body label in the Purkinje cell layer and scattered punctate label in the molecular layer during early larval through 

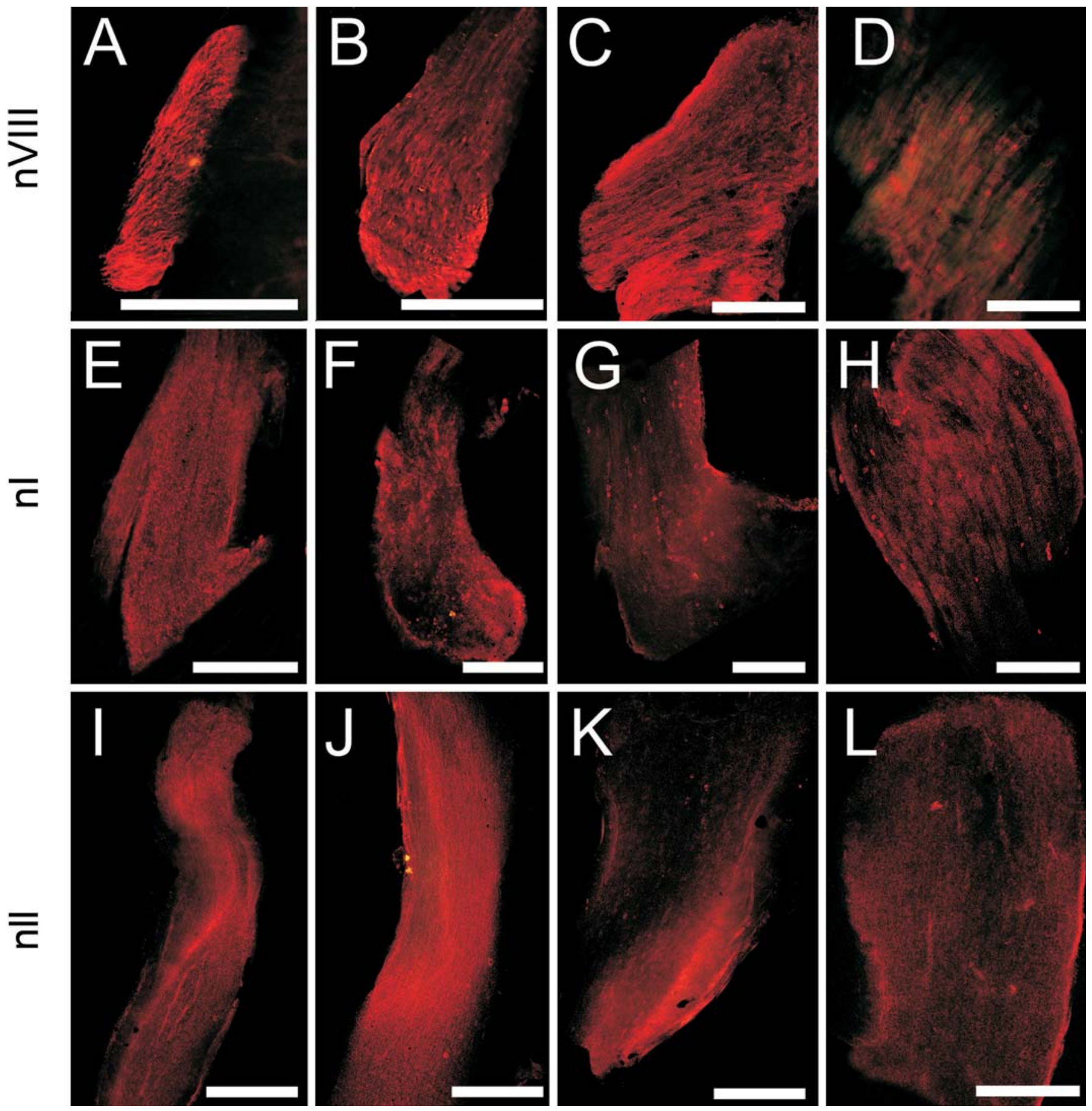

Fig. 3. Sections through cranial nerves (nVIII, nI, nII) processed for GAP-43 show immunoreactivity at all developmental stages. GAP-43 fluoresces red (color online only). In these images, all nerve segments from a particular cranial nerve are oriented in approximately the same direction. A-D Label in nVIII. A Heavy label in a stage 23 (hatchling) tadpole. B Heavy label in a stage 34 (late larval) tadpole. C Heavy label in a stage 45 (metamorphic climax) tadpole. D Light label in an adult frog. Scale bars $=200 \mu \mathrm{m}$ for images $\mathbf{A}-\mathbf{C} ; 50 \mu \mathrm{m}$ for image $\mathbf{D}$. E-H Label in nI. E Heavy immunolabeling in a stage 31 (late

larval) animal. F Moderate immunolabeling in a stage 38 (deaf period) animal. G Light immunolabeling in a stage 42 (metamorphic climax) animal. $\mathbf{H}$ Light immunolabeling in a subadult frog. I-L Label in nII. I Moderate immunolabeling in a stage 31 animal. J Moderate immunolabeling in a stage 38 animal. K Light immunolabeling in a stage 42 (metamorphic climax) animal. L Light immunolabeling in a subadult frog. All images from $\mathrm{nI}$ and $\mathrm{nII}$ were taken from the same animal at that developmental stage. Scale bar for images E-L Scale bars $=200 \mu \mathrm{m}$. 

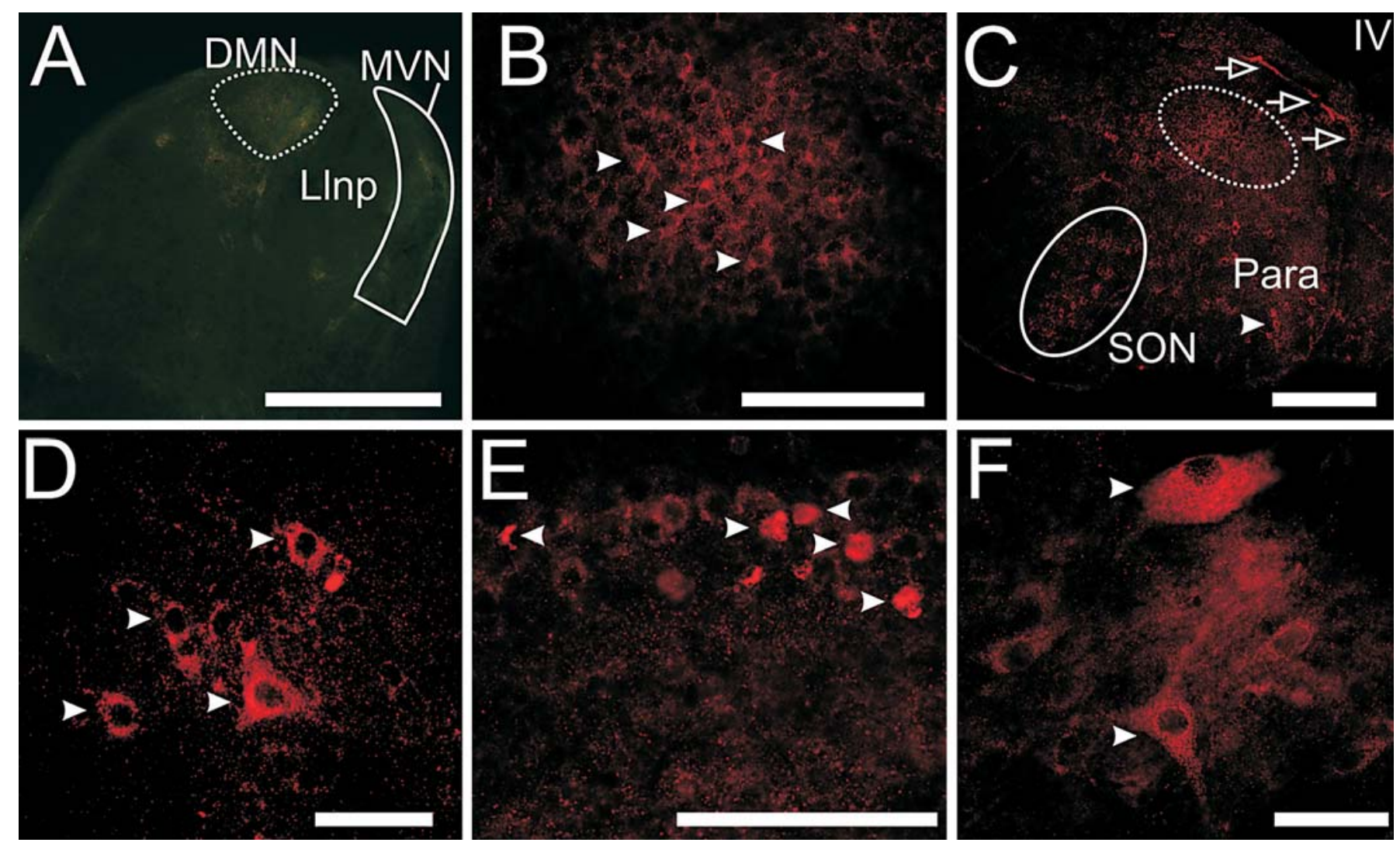

Fig. 4. GAP-43 immunoreactivity in the medulla and cerebellum varies across development. All images are oriented such that dorsal is up. A Coronal section (medial to the right) showing no GAP43 label above background in the DMN (dotted outline) or in the MVN (solid outline) in a stage 27 (early larval) animal. The LLnp is the unstained area between these two nuclei. This image has been contrast-enhanced to show nuclear boundaries. The orangeyellow staining probably represents lipofuscin (color online only). Scale bar $=200 \mu \mathrm{m}$. B High power shot of moderate label in the MVN (at approximately the same rostral/caudal location as in $\mathbf{A}$ ) of a stage 45 (metamorphic climax) tadpole. The five arrowheads point to examples of labeled cell bodies. Medial is to the right in this image. Scale bar $=100 \mu \mathrm{m}$. C Light, diffuse label of the re- ticular gray (dotted outline) and of the SON (solid outline) in a stage 36 (late larval) tadpole. Hollow arrows show label of dorsal arcuate fibers. The arrow head points to a labeled soma in the paragigantal nucleus (Para). Medial is to the right in this image. Scale bar $=200 \mu \mathrm{m}$. D High power micrograph of labeled soma in the SON of a stage 45 tadpole. Four cells are shown (solid arrowheads). This image is at approximately the same rostral/caudal position as image C. Medial is to the right. Scale bar $=50 \mu \mathrm{m}$. E Label in the Purkinje cell layer of the cerebellum of a subadult frog. Five cells are shown (solid arrowheads). Scale bar $=100 \mu \mathrm{m}$. F High power photomicrograph of label in the cerebellar nucleus of an adult frog. Two cells are shown (solid arrowheads). Scale bar $=50 \mu \mathrm{m}$. metamorphic climax stages. Perikaryl and punctuate label in the cerebellar nucleus are both moderate from late larval through climax stages. After the completion of climax, label is typically light, but with clear label of perikarya and of puncta remaining in both of these brain areas (Purkinje cell layer, fig. 4E, subadult; cerebellar nucleus, fig. 4F, adult).

Immunolabeling in the optic tectum (OT) and in the torus semicircularis (TS) of the midbrain (fig. 5) is typically concentrated in the layers surrounding and adjacent to the optic ventricle (layers 1-6 of the OT, laminar nucle- us of the TS), with lighter label of the superficial layers (7-9) of OT and of the principal and magnocellular nuclei of the TS. In hatchlings (fig. 5A, stage 23), intense diffuse label of neuropil in deep layers of the OT is visible, with label of superficial layers confined to the lateral margin of the OT near the approximate site of projections from nII as previously identified [Reh and Constantine-Paton, 1984]. There is also intense diffuse label in the area of the laminar nucleus of the TS, in areas bordering the tegmental ventricle, and of presumptive fibers in the ventral margin of the brain. In both hatchlings and early larval ani- 
Fig. 5. GAP-43 immunoreactivity in the midbrain varies in intensity and in its distribution within the midbrain across development. A Coronal section through the midbrain of a stage 23 hatchling. Heavy but diffuse label is concentrated around the ventricular zones and in lateral regions of the OT. Scale bar $=200 \mu \mathrm{m}$. B Sagittal section through the brainstem of a stage 26 (early larval) tadpole. There is intense immunoreactivity in fiber bundles coursing through the brainstem, with fibers extending up to the OT and TS clearly outlined (hollow arrows). OV = Optic ventricle. Scale bar $=500 \mu \mathrm{m}$. C Coronal section showing discrete, moderate label in the deep layers of the OT, the laminar nucleus and dorsal principal nuclei of the TS in a stage 36 (late larval) tadpole. Individual labeled cells in deep layers of OT (2 cells are shown) and in the laminar nucleus ( 4 cells are shown) are indicated by the solid arrowheads. The hollow arrow shows intense fiber and cell label in layer 6 of the OT. Dorsal is up, medial is to the right. Scale bar $=200 \mu \mathrm{m}$. D Heavy label of both superficial (arrows) and deep (arrowheads) layers of the OT in a stage 45 (metamorphic climax) animal. There is also heavy label (solid arrowheads) in the laminar nucleus. In this image, medial is to the left. Scale bar $=200 \mu \mathrm{m}$. E High power photomicrograph of label in the ventricular zone dorsal to the laminar nucleus of a froglet. Two cells are shown (solid arrowheads). In this image, dorsal is up, medial is to the right. Scale bar $=50 \mu \mathrm{m}$. F Label in the ventricular zone (3 cells are shown; solid arrowheads) and in the laminar nucleus (2 cells are shown; hollow arrowheads) of an adult animal. In this image, dorsal is up and medial is to the right. Scale bar $=50$ $\mu \mathrm{m}$.
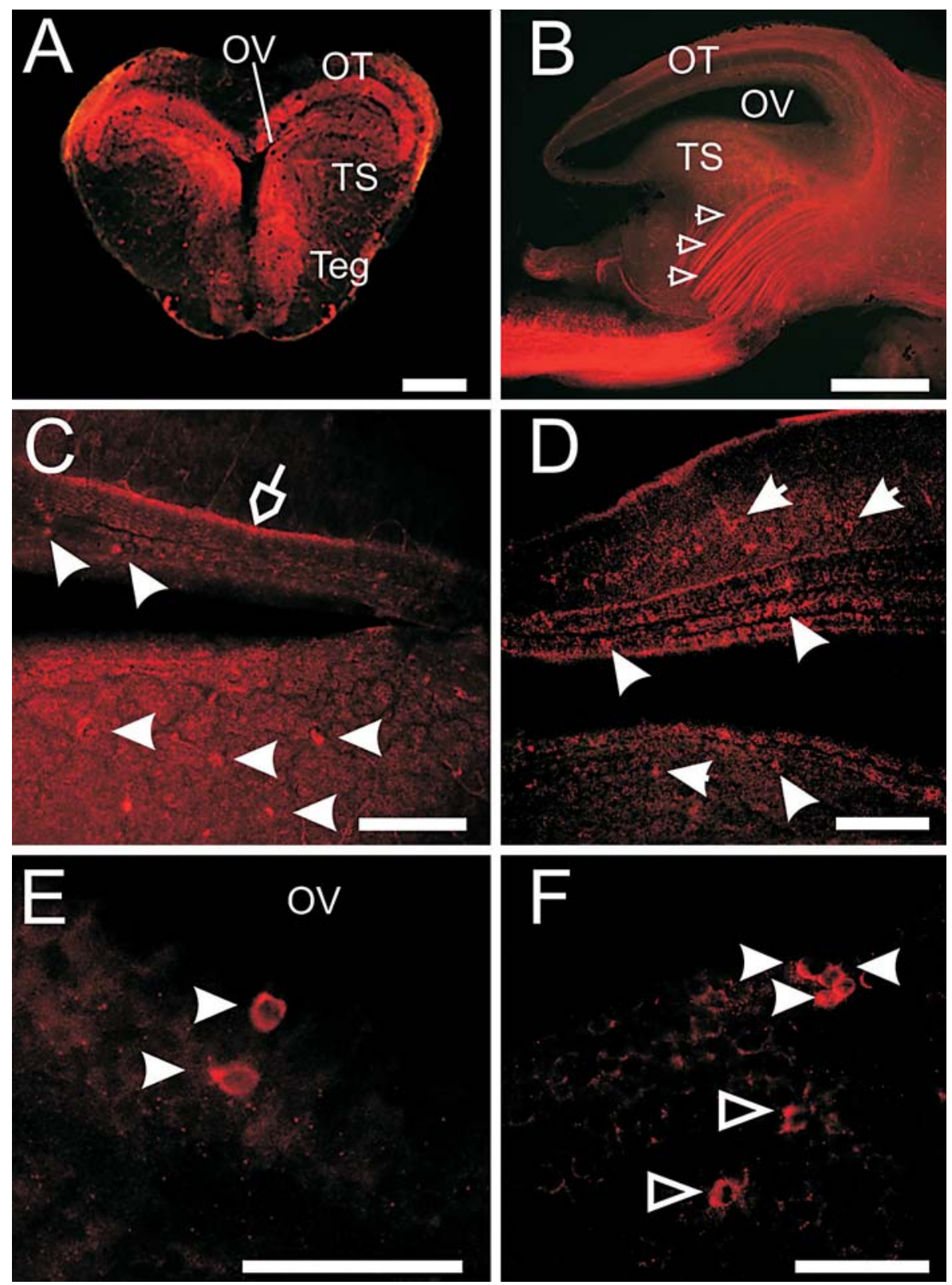

mals (fig. 5B, stage 26), and extending throughout larval development (data not shown), intense staining of fiber bundles, including presumptive lateral lemniscal fibers, is observed. In the early larval period, moderate diffuse label is initially seen in the ventricular zone and in neuropil surrounding the optic ventricle (layers $2-6$ of the OT and the laminar nucleus of the TS). In late larval animals, this label becomes more discretely distributed, with clearly defined label of cell bodies and of fibers (fig. 5C, stage 36). Scattered label of perikarya also appears in the most dorsal part of the principal nucleus of the TS; however, there is minimal to no label of superficial layers of the OT during these stages. From late larval and extending into metamorphic climax stages, there is considerable label along the tegmental ventricle and along the ventral border of the midbrain, consistent with the location of major fiber tracts (data not shown). During metamorphic climax, immunolabeling is overall more intense and is more widely distributed, with clear label of cell bodies in both superficial and deep layers of the OT and the laminar nucleus (fig. 5D, stage 45), and scattered throughout both dorsal and ventral regions of the principal nucleus. Immunolabel de- 

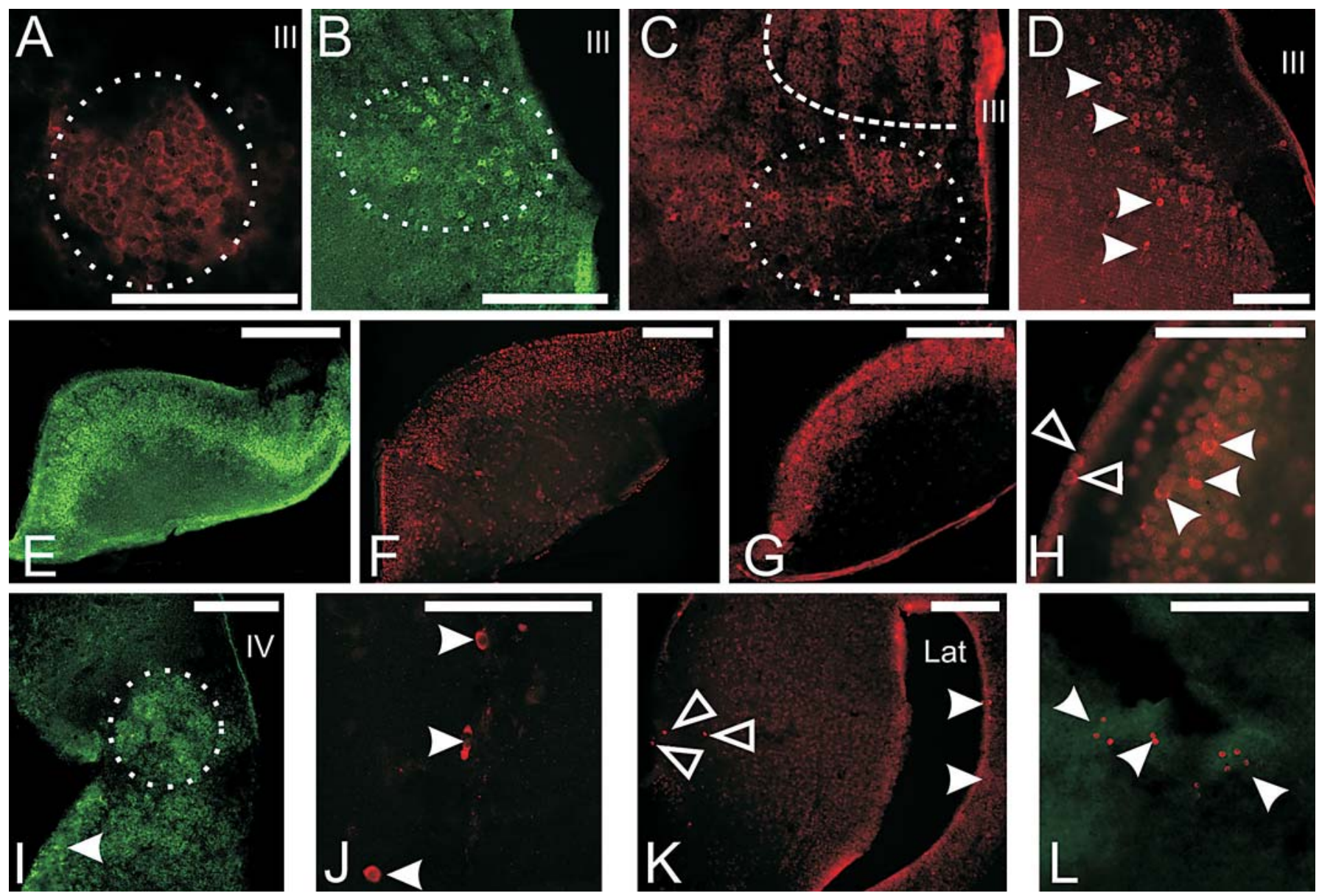

Fig. 6. GAP-43 label in forebrain nuclei persists throughout larval development and into adult frogs. Images A-D are all at the same approximate rostral/caudal position. In these images, dorsal is up and medial is to the right. III = Third ventricle. A Heavy but diffuse label in the ventromedial nucleus of the thalamus (demarcated by dashed circle) in a stage 27 (early larval) tadpole. In this image, dorsal is up and medial is to the right. Scale bar $=100 \mu \mathrm{m}$. B Heavy and more discrete label in the ventromedial nucleus (dashed circle) and in the ventricular area of a stage 34 (late larval) tadpole. Scale bar $=200 \mu \mathrm{m}$. C Heavy label in the central nucleus (large dashed circle) and in the ventromedial nucleus (small dashed circle) of the thalamus in a stage 38 (deaf period) tadpole. Scale bar $=200 \mu \mathrm{m}$. D Moderate label in the ventromedial nucleus of an adult bullfrog. The four solid arrowheads point to individual labeled soma. Scale bar $=200 \mu \mathrm{m}$. Images E-H were all taken at approximately the same rostral/caudal position. In these images, dorsal is up and medial is to the left. E Heavy, diffuse label around the ventricular zone of the ventral hypothalamus of a stage 34 tadpole. Scale bar $=200 \mu \mathrm{m}$. F Heavy, discrete label in the ventral hypothalamus of a stage 45 (metamorphic climax) tad- pole. Scale bar $=200 \mu \mathrm{m}$. G Moderate, discrete label around the ventricular zone of the ventral hypothalamus in a froglet. Scale bar $=200 \mu \mathrm{m}$. H Light, discrete label in the ventricular zone (two hollow arrowheads) and immediately adjacent cell layers (three solid arrowheads) in the ventral hypothalamus of an adult frog. Scale bar $=100 \mu \mathrm{m}$. Images $\mathbf{I}-\mathbf{L}$ were taken at the same approximate rostral/caudal position. In these images, dorsal is up and medial is to the right in I and to the left in $\mathbf{J}-\mathbf{L}$. I Moderate diffuse label in the ventricular zone (solid arrowhead) and in the medial septum (dashed circle) of a stage 34 tadpole. IV = Fourth ventricle. Scale bar $=200 \mu \mathrm{m}$. J Moderate discrete label (solid arrowheads) in the medial septum in a stage 40 (deaf period) tadpole. Scale bar $=100 \mu \mathrm{m}$. K Light label around the ventricular zone of the lateral pallium (solid arrowheads) and in the medial septum (hollow arrowheads) in a froglet. Scale bar $=200 \mu \mathrm{m}$. Lat $=$ Lateral ventricle. $\mathbf{L}$ Light label in the ventricular zone near the ventral striatum (three solid arrowheads) in an adult frog. Scale bar $=200$ $\mu \mathrm{m}$. In images B, E, I, GAP-43 fluoresces green. In all other images, GAP-43 fluoresces red (color online only). 
clines in intensity in the froglet midbrain and is mostly restricted to the ventricular zone and to immediately adjacent cell layers (fig. 5E). The distribution of label in subadults and adults (fig. 5F) is typically lighter than that seen in froglets, but labeled perikarya are still visible in the same general brain areas.

\section{Forebrain}

Immunolabeling for GAP-43 in selected forebrain areas at different developmental stages is shown in figure 6 . Cell layers surrounding the third ventricle in both the thalamus and hypothalamus exhibit moderate to heavy label throughout larval development, declining to moderate to light label in postmetamorphic animals. In the thalamus, all medially-located nuclei that can be identified in larval animals [Horowitz and Simmons, 2007] exhibit both punctal and perikaryal label, with particularly heavy label of the ventromedial nucleus (fig. $6 \mathrm{~A}$, stage $27 ; 6 \mathrm{~B}$, stage 34 ), central nucleus (fig. 6C, stage 37 ), and anterior and posterior nuclei. There is also moderate label of the posterior commissure and the habenula. In postmetamorphic animals, label is mostly confined to the ventricular zone and immediately adjacent cell layers, although moderate to light label of perikarya and puncta in the ventromedial nucleus can still be seen (fig. 6D, adult). From hatchling through late larval stages, there is heavy, diffuse label of the dorsal and ventral hypothalamus, mostly confined to the ventricular zone and adjacent neuropil (fig. $6 \mathrm{E}$, stage 34). Beginning in the deaf period and into metamorphic climax (fig. 6F, stage 45), label becomes more discrete, but is still mostly confined to the ventricular zone and immediately adjacent cell layers. Immunolabeling persists at a moderate level in froglets (fig. 6G) and at light levels in subadults and adults (fig. 6H). GAP- 43 immunolabel of the preoptic area is light to moderate throughout larval stages (data not shown).

GAP-43 immunolabel in the telencephalon (fig. 6I-L) in all developmental stages is mostly concentrated around the lateral ventricles in both dorsal and ventral regions. Labeled cell bodies are also observed in the medial septum (fig. 6I, stage 34; fig. 6J, stage 40) and in the ventral striatum (fig. 6L, adult). No labeled perikarya or fibers were observed in the amygdala at any developmental stage.

\section{Discussion}

Here we show that expression of growth-associated protein GAP-43 in the bullfrog's brain varies across the developmental span from hatchling tadpole to adult, but with different patterns of expression in different neural areas and with widespread, intense expression during metamorphic climax. Given the proposed relationships between GAP-43 expression and functional and structural neural plasticity [Skene, 1989; Benowitz and Routtenberg, 1997], these data emphasize the highly plastic nature of the brain of the bullfrog at all stages of development, with particular emphasis on the period of metamorphic climax. Further, our data allow predictions about the spatial and temporal distribution of anatomical changes in particular brain areas across development in these animals, and their possible relation to changes in function across metamorphosis and to the regenerative capacity of the adult bullfrog nervous system.

\section{Methodological Considerations}

The protein GAP-43 is evolutionarily conserved [Jacobson et al., 1986; Skene, 1989]. The cDNA sequence of Xenopus GAP- 43 is $78 \%$ homologous with that of rat GAP43 [Schrama et al., 1997]; rat and mouse GAP-43 are 92\% homologous [Genbank search]. GAP-43 was first characterized in adult toad optic nerve after induced injury [Skene and Willard, 1981]. Jacobson et al. [1986] and Skene et al. [1986] confirmed that the proteins from growth cone membrane fractions in fetal and adult rat brain are electrophoretically similar to that from toad. The commercial GAP-43 antibody used in our experiments has been reported to show wide interspecies cross-reactivity, consistent with this previous literature. Yet it is also known that the apparent molecular weight of GAP- 43 protein can differ among species, within a range of about $43-57 \mathrm{kDa}$. Jacobson et al. [1986] reported, for example, an apparent molecular weight of $48-51 \mathrm{kDa}$ in protein from adult rat cerebral cortex and $47-48 \mathrm{kDa}$ from adult toad optic nerve. These estimates of molecular weight also differ from those obtained in earlier work from the same group [ $40-45 \mathrm{kDa}$; Skene and Willard, 1981]. These small discrepancies in apparent molecular weight have been attributed to the unusual behavior of GAP-43 protein in electrophoresis, such that its apparent molecular weight varies with the acrylamide concentration of gels [Jacobson et al., 1986]. In fact, this aberrant behavior of the protein on gels has been used as one of its defining characteristics [Jacobson et al., 1986; Skene, 1989]. In this respect, small differences in apparent molecular weight among species and different gel concentrations (and presumably, different antibody sources) are not unexpected. In different anuran species, the apparent molecular weight of GAP-43 varies within the range of 41-63 kDa [Jacobson et al., 1986; Golding and Tonge, 1993; Schrama et al., 1997; Soto et al., 2003]. Our data consis- 
tently show a discrete band around $43 \mathrm{kDa}$ in all bullfrog brains that we tested. Given that these bands are within the range reported in other experiments, that the bands we observed from rodent brain lysate are within the range reported in the literature, and that no nonspecific binding was present in the negative control experiments, we are confident that the antibody we used recognized GAP-43 protein in our tissue.

Our data also show in both larval and adult frog tissue the presence of a weaker band at around $40 \mathrm{kDa}$. The presence of two bands has been noted in other work with adult anuran brains, although the exact molecular weight of these bands differs from what we observed [Golding and Tonge, 1993; bands at 53.5 and $63 \mathrm{kDa}$. Even in mammalian tissue, two bands within the range of about 45-55 $\mathrm{kDa}$ can sometimes be observed (as shown in figure 1), particularly when high concentrations of the antibody are used (Sigma product information sheets). Haynes et al. [2005] also reported two bands in white matter tissue from human fetuses (gestational ages 21-41 weeks). They suggested that the weaker second band at the lower molecular weight represents a degradation product resulting from the presence of very high levels of the protein.

Our immunohistochemical data are based on tissue processed according to standardized protocols in which all steps are monitored and parameters kept constant. In addition, tadpole tissue was processed in mixed stage batches as a further control for any unexpected variability in either antibody viability or in procedures. Tissue processed without primary or secondary antibody showed no staining above background levels. Our description of temporal and spatial patterns of GAP- 43 immunolabel is based on qualitative evaluation of intensity of staining in particular brain areas. Quantification was difficult to perform and to compare in tadpole tissue, because of the change in staining from a diffuse to a more discrete pattern as development proceeded. Qualitative descriptions of intensity of immunolabel are commonly reported in the literature [Skene et al., 1986; Golding and Tonge, 1993; Horváth et al., 1997; Haynes et al., 2005]. Given that our focus is on comparing distribution and intensity of label across stages, and given that our experiments proceeded with standard protocols and tight controls, any error in qualitative judgments should be similar both within and between developmental stage groups.

\section{Species Similarities and Differences in GAP-43}

Immunoreactivity

As predicted from results of both immunohistochemisty and in situ hybridization in other developing animals
[Jacobson et al., 1986; Dani et al., 1991; Golding and Tonge, 1993; Illing et al., 1999; Feig, 2005], immunoreactivity for GAP-43 in the bullfrog's brain is overall more intense and more widely distributed in younger (larval) than in older (postmetamorphic) bullfrogs. Immunolabel is diffuse in the earliest larval animals, becoming more discrete, with clearly defined label of cell bodies and of puncta surrounding unlabeled cell bodies, in older larval animals, as also observed in rats across early postnatal development [Horváth et al., 1997]. During metamorphic climax, immunolabel is moderate to heavy in most brain regions we identified; in the medulla and pons, label is overall more intense in climax than in early or later stages. In general, we observed a pattern of immunoreactivity at most periods of development (excluding climax) in which label is overall more intense in the diencephalon than in the rhombencephalon or mesencephalon. Benowitz et al. [1988] interpreted their data in adult rats as showing a caudal-to-rostral gradient of increasing GAP43 immunoreactivity along the neuraxis. Our data show a trend consistent with this, although with reduced expression in the telencephalon compared to that in the diencephalon. This might reflect the overall less differentiated state of the bullfrog compared to the mammalian telencephalon.

Benowitz et al. [1988] and Chaisuksunt et al. [2000] reported no or only minimal expression of GAP-43 protein and mRNA, respectively, in medullary nuclei in the adult mammalian brain. Our data in adult bullfrogs, showing no or minimal immunoreactivity in the DMN, MVN and SON are consistent with these findings. On the other hand, Horváth et al. [1997] and Illing et al. [1999] observed considerable protein and mRNA expression in the SON of adult rats, with less, but still observable, immunoreactivity in the cochlear nucleus complex. The reasons for these discrepancies in the mammalian data are unclear.

In adult rats, GAP-43 immunolabel in both the superior and inferior colliculi has been described as minimal to modest [Benowitz et al., 1988]. In adult ranids, Golding and Tonge [1993] reported that immunolabeling for GAP43 in the OT was mainly restricted to the caudalmost portion of this nucleus, whereas Soto et al. [2003] reported that immunolabel was present mainly in the superficial layers. Although our data confirm the presence of GAP-43 immunolabel in the adult bullfrog OT, we observed label to be concentrated around the optic ventricle and in adjacent deep layers at both caudal and rostral levels. We observed no to minimal label of superficial OT layers at any developmental stage, except during meta- 
morphic climax, where moderate to heavy label was present throughout the OT. Our observation that light to moderate immunoreactivity is present in the torus semicircularis of postmetamorphic bullfrogs is consistent with the detectable levels of GAP- 43 mRNA expression in the inferior colliculus of the adult rat [Illing et al., 1999].

One striking and consistent finding of GAP-43 expression in the mammalian brain is its presence in the hippocampus [Oestreicher and Gispen, 1986; Benowitz et al., 1988; McGuire et al., 1988; Neve et al., 1988]. These data have been interpreted as evidence of the role of this brain area in synaptic plasticity, learning, and memory. We did not observe any measurable or consistent GAP-43 label in the medial pallium, an area that has been proposed as homologous to the hippocampus [Northcutt and Ronan, 1992]. We did observe, on the other hand, consistent GAP-43 label in the area we identified as the medial septum. González and López [2002] proposed that the medial septum in frogs provides input to the medial pallium by a pathway that might be homologous to the septohippocampal pathway of mammals. Studies in rats show that GAP-43 mRNA expression in the medial septum ranges from moderate [young and old animals; Ferrini et al., 2002] to low [adults; Haas et al., 2000], but is strongly up-regulated after damage to septohippocampal fibers [Haas et al., 2000]. Our finding of light to moderate GAP-43 immunolabel in the medial septum is consistent with these data. This suggests that the medial septum in bullfrogs might be an important telencephalic area underlying plasticity, both during larval development and into adulthood. It is also interesting that the anterior and ventromedial thalamic nuclei, which show moderate to heavy GAP-43 immunoreactivity at all developmental stages, project to the septal nuclei [Roden et al., 2005]. These projections have been interpreted as conveying multimodal information and as part of a 'limbicassociative' pathway [Westhoff et al., 2004; Roden et al., 2005]. Together, these data are consistent with the hypothesis of GAP-43 as a marker of brain areas that play an important role in plasticity.

One interesting comparison between our data in the bullfrog and those in mammals concerns the degree of immunolabel in the cerebellum. Immunolabel in the adult rat cerebellum has been characterized as sparse or minimal, and confined to the molecular or granular layers [Oestreicher and Gispen, 1986; Benowitz et al., 1988], whereas mRNA expression is low to moderate in the granular layer and low in the molecular layer [Chaisuksunt et al., 2000]. These studies are consistent in showing no GAP-43 expression in the Purkinje cell layer in the normal cerebellum. This is in marked contrast to our results in the bullfrog, where light immunoreactivity is observed in the adult Purkinje cell layer, even in adult frogs. The lack of GAP-43 expression in mammalian Purkinje cells has been related to the inability of these cells to spontaneously regenerate after axotomy [Chaisuksunt et al., 2000]. Our data raise the possibility that Purkinje cells in the frog brain might contain spontaneous regenerative potential.

We also show consistent immunolabeling for GAP-43 in cranial nerves nI, nII, and nVIII in tadpoles and in postmetamorphic animals. It is well known that cranial nerves in adult anurans can regenerate after injury [e.g., Skene and Willard, 1981] and can reform functional synapses with central target sites [e.g., Zakon and Capranica, 1981]. Our data in normal animals are thus consistent with previous work demonstrating increased synthesis of this protein during axonal regeneration in other species of frogs as well as in other non-mammals [Benowitz et al., 1981; Skene and Willard, 1981; Benowitz and Lewis, 1983; Golding and Tonge, 1993; Soto et al., 2003]. The constitutive expression of GAP-43 in cranial nerves in adult frogs might form the basis for this regenerative ability.

\section{Possible Correlates with Developmental Changes in Function}

Our data highlight changes in GAP-43 immunoreactivity throughout larval development in different brain areas and at different developmental stages. Of interest in the interpretation of these findings is the question of how these immunohistochemical changes might correlate with anatomical and functional reorganization of the brain over metamorphosis. One striking finding in our experiments is the consistent, intense expression of GAP43 in most brain areas during metamorphic climax, the time of final transition from aquatic to semi-terrestrial life. This high expression of GAP-43 suggests that the transition from tadpole to frog reflects considerable anatomical and perhaps functional plasticity in the brain during this crucial developmental time. This correlation is predicted from the widespread changes that occur in all sensory and motor systems at climax. These changes include the initial emergence and final differentiation of forelimbs, the transformation of the narrow tadpole oral disk to the wide frog mouth, the final movement of the eyes from a more lateral to a more medial and dorsal position on the head, the final degeneration of the lateral line system, and the development of the tympanic-columellar transduction system [Shi, 1999; Simmons and 
Horowitz, 2007]. Changes in external body morphology and in peripheral sensory structures would be expected to produce concomitant changes in neural anatomy. Indeed, during metamorphic climax there is considerable anatomical reorganization of the brainstem associated with some of these external changes [Fritzsch et al., 1984; Kumaresan et al., 1998]. Little is known, however, about possible anatomical changes in the ranid diencephalon [Horowitz and Simmons, 2007] or telencephalon across larval development. Moreover, there is only limited information on functional changes in central nuclei during metamorphosis, and most of this information derives from the study of neural processing in auditory/vestibular pathways. Nonetheless, some correspondences can be drawn, and some directions for future work proposed.

Anatomical changes in the brainstem over larval development include the degeneration of the lateral line nuclei beginning in early stages of metamorphic climax; the disruption of anatomical connectivity between the SON and the ipsilateral TS at the end of the late larval period (the deaf period, stages 38-41); the subsequent re-appearance of this connectivity during climax; and the appearance of connectivity between the SON and the contralateral TS projections also during climax [Boatright-Horowitz and Simmons, 1997; Horowitz et al., 2007a; Simmons and Horowitz, 2007]. Consistent with these anatomical changes, both the SON and TS exhibit their heaviest immunolabel for GAP-43 during climax, compared to any other developmental stage. Deriving from the reported association of GAP-43 with axonal growth cones [Meiri et al., 1986; Skene et al., 1986], the increased expression of this protein in the SON and in the TS during climax might reflect the new fiber growth reversing the loss of connectivity during the deaf period, where fibers presumably retracted or degenerated, and the appearance and/or strengthening of the contralateral pathway. There are considerable functional changes in the TS across development that parallel these changes in anatomical connectivity and in GAP-43 immunolabel. In particular, auditory-responsive cells vary in tuning curve sharpness, best frequencies, and ability to phase-lock to the envelopes of sounds [Boatright-Horowitz and Simmons, 1997; Boatright-Horowitz et al., 1999], with the most pronounced changes occurring during the deaf period and metamorphic climax. The MVN also shows functional changes in response properties, this time to the particle motion component of sounds, beginning in metamorphic climax [Horowitz et al., 2007b], a time of increased GAP-43 immunoreactivity in this brain area, also. There are no developmental functional data available on neural processing in the SON to make any correlations with changes in patterns of GAP-43 expression.

The DMN also undergoes structural changes during larval development, gradually migrating from a more lateral position in the medulla at hatchling stages, to a more dorsal/medial position during the deaf period and early climax stages [Kumaresan et al., 1998]. In this case, there is no or minimal immunolabel of GAP-43 at any larval stage, and thus no correlation with these anatomical changes. This suggests that the presence of GAP- 43 protein is not obligatory for metamorphic changes in this brain nucleus. There are no functional data available, however, to determine if DMN response properties vary along with the change in the position of this nucleus. Because DMN migration extends through a longer duration time-course measured in weeks to months rather than the relatively more abrupt changes seen in SON-TS pathways which are typically completed in days, there might be no need for changes in GAP-43 levels in the DMN as compared to the dramatic up-regulation seen in these faster-changing nuclei, or the changes could simply be more difficult to detect using the methods reported here.

The pattern of GAP-43 expression in the OT is similar to that in the TS. In visual pathways of several anuran species, anatomical changes during larval development include the progressive expansion of terminations of retinal ganglion fibers from the rostral/lateral to the caudal/ medial contralateral OT, the progressive growth of the more superficial layers of the OT compared to the deep layers, and the development and elaboration of ipsilateral retinotectal and retinothalamic projection pathways during climax [Currie and Cowan, 1975; Hoskins, 1986; Kollros and Thiesse, 1988]. Specifically in the bullfrog, the cell layers of the OT become more pronounced as larval development proceeds, although the major change in thickness and differentiation of these layers seems to have occurred by the end of the hatchling period [Horowitz and Simmons, 2007]. It is interesting to note that GAP-43 immunolabel is intense, but diffuse, in the OT during hatchling stages. There are no functional data available on response properties in the bullfrog OT to determine how function might vary over development. If changes in function are somehow related to GAP-43 expression, we would expect to see these both at hatchling stages and again at climax.

Compared to these brainstem nuclei, the diencephalon and telencephalon both exhibit less variability in the intensity and distribution of GAP-43 label across larval development, with moderate to heavy label observed at 
all stages examined. This relative stability of GAP-43 expression is interesting, given the limited changes in the gross nuclear organization of the diencephalon over larval development, compared to that of both the dorsal medulla and the TS [Horowitz and Simmons, 2007]. The high levels of GAP-43 expression in the hypothalamus might be related to the role of this nucleus in regulating levels of circulating hormones, which vary in complex patterns over development [Denver, 1998; Shi, 1999]. Future work should examine the relationship among levels of GAP-43 expression, possible changes in afferent and efferent connectivity, and functional development of these nuclei.

GAP-43 is expressed in neural precursor cells [Esdar et al., 1999], in cells after completion of mitosis [Dani et al., 1991], and in axon growth cones, neurites and immature synaptic terminals [Meiri et al., 1986; Skene et al., 1986]. Consistent with these findings, our data show some parallels between GAP-43 immunoreactivity and periods of cell proliferation in both the SON and the TS. Both of these brainstem nuclei show peaks of cell proliferation, as indexed by increased numbers of cells labeled with BrdU, during metamorphic climax [Chapman et al., 2006; Simmons et al., 2006], the time period during which GAP-43 expression is also intense. A subset of these newly-born cells might form processes, and the formation of these processes might be reflected in increased GAP-43 expression. This relationship does not extend to the DMN, however; although this nucleus also exhibits a peak of cell proliferation at metamorphic climax, it shows minimal GAP-43 expression during this time. There are no published data on BrdU histochemistry in the other areas of the tadpole brain that would allow further assessment of this proposed relationship. Kollros and Thiesse [1988] observed peaks of mitotic activity, as indexed by determination of mitotic figures in hematoxylin-stained tissue, in the OT of $R$. pipiens in late larval stages, a time period where our data show that GAP-43 immunoreactivity is less intense than at climax. Those brain areas (OT, TS, hypothalamus, telencephalon) that continue to show some expression of GAP-43 during adulthood are also those areas that continue to show proliferation of new cells in adulthood [Simmons et al., 2008]. The finding that GAP-43 is expressed in precursor cells [Esdar et al., 1999] is consistent with our observation that GAP-43 labeled cells in the telencephalon are concentrated in the ventricular zones.

\section{Acknowledgements}

This research was supported by NIH grant R01 DC05257 (AMS, SSH), F31 DC006776 (JAC) and by an undergraduate fellowship from the Rhode Island Space Grant Consortium (RAB).

\section{References}

Benowitz LI, Lewis ER (1983) Increased transport of 44,000 - to 49,000-dalton acidic proteins during regeneration of the goldfish optic nerve: a two-dimensional gel analysis. J Neurosci 3:2153-2163.

Benowitz LI, Routtenberg A (1997) GAP-43: an intrinsic determinant of neuronal development and plasticity. Trends Neurosci 20:8491.

-Benowitz LI, Apostolides PJ, Perrone-Bizzozero N, Finklestein SP, Zwiers H (1988) Anatomical distribution of the growth-associated protein GAP-43/B-50 in the adult rat brain. J Neurosci 8:339-352.

- Benowitz LI, Perrone-Bizzozero NI, Neve RL, Rodriguez W (1990) GAP-43 as a marker for structural plasticity in the mature CNS. Prog Brain Res 86:309-320.

- Benowitz LI, Shashoua VE, Yoon MG (1981) Specific changes in rapidly transported proteins during regeneration of the goldfish optic nerve. J Neurosci 1:300-307.
Boatright-Horowitz SS, Simmons AM (1997) Transient 'deafness' accompanies auditory development during metamorphosis from tadpole to frog. Proc Natl Acad Sci USA 94: 14877-14882.

- Boatright-Horowitz SS, Garabedian CE, Odabashian KH, Simmons AM (1999) Coding of amplitude modulation in the auditory midbrain of the bullfrog across metamorphosis. J Comp Physiol A 184:219-231.

Chaisuksunt V, Zhang Y, Anderson PN, Campbell G, Vaudano E, Schachner M, Lieberman AR (2000) Axonal regeneration from CNS neurons in the cerebellum and brainstem of adult rats: Correlation with the patterns of expression and distribution of messenger RNAs for L1, CHL1, c-jun and growth-associated protein-43. Neuroscience 100:87108.

Chapman JA, Weinstein JL, Simmons AM (2006) Cell proliferation in the Rana catesbeiana auditory medulla over metamorphic development. J Neurobiol 66:115-133.
Currie J, Cowan WM (1975) The development of the retino-tectal projection in Rana pipiens. Dev Biol 46:103-119.

Dani JW, Armstrong DM, Benowitz LI (1991) Mapping the development of the rat brain by GAP-43 immunocytochemistry. Neuroscience 40:277-287.

Dent EW, Meiri KF (1998) Distribution of phosphorylated GAP-43 (neuromodulin) in growth cones directly reflects growth cone behavior. J Neurobiol 35:287-299.

- Denver RJ (1998) The molecular basis of thyroid hormone-dependent central nervous system remodeling during amphibian metamorphosis. Comp Biochem Physiol C Pharmacol Toxicol Endocrinol 119:219-228.

- Esdar C, Oehrlein SA, Reinhardt S, Maelicke A, Herget T (1999) The protein kinase C (PKC) substrate GAP-43 is already expressed in neural precursor cells, colocalizes with $\mathrm{PKC} \eta$ and binds calmodulin. Eur J Neurosci 11:503-516. 
Feig SL (2005) The differential distribution of the growth-associated protein-43 in first and higher order thalamic nuclei of the adult rat. Neuroscience 136:1147-1157.

-Ferrini M, Bisagno V, Piroli G, Grillo C, Deniselle MCG, DeNicola AF (2002) Effects of estrogen on choline-acetyltransferase immunoreactivity and GAP-43 mRNA in the forebrain of young and aging male rats. Cell Mol Neurobiol 22:289-301.

-Fritzsch B, Nikundiwe AM, Will U (1984) Projection patterns of lateral line afferents in anurans: A comparative HRP study. J Comp Neurol 229:451-469.

Golding JP, Tonge DA (1993) Expression of GAP43 in normal and regenerating nerves in the frog. Neuroscience 52:415-426.

-González A, López JM (2002) A forerunner of septohippocampal cholinergic system is present in amphibians. Neurosci Lett 327: 111-114.

Gosner KL (1960) A simplified table for staging anuran embryos and larvae with notes on identification. Herpetologica 16:183-190.

-Haas CA, Hollerach E, Deller T, Naumann T, Frotscher M (2000) Up-regulation of growthassociated protein $43 \mathrm{mRNA}$ in rat medial septum neurons axotomized by fimbria-fornix transection. Eur J Neurosci 12:42334242.

-Haynes RL, Borenstein NA, Desilva TM, Folkerth RD, Liu LG, Volpe JJ, Kinney HC (2005) Axonal development in the cerebral white matter of the human fetus and infant. J Comp Neurol 484:156-167.

-Horowitz SS, Simmons AM (2007) Dynamic visualization of the developing nervous system of the bullfrog, Rana catesbeiana. Brain Res 1157:23-31.

-Horowitz SS, Chapman JA, Simmons AM (2007a) Plasticity of auditory medullarymidbrain connectivity across metamorphic development in the bullfrog, Rana catesbeiana. Brain Behav Evol 69:1-19.

- Horowitz SS, Tanyu LH, Simmons AM (2007b) Multiple mechanosensory modalities influence development of auditory function. J Neurosci 27:782-790.

Horváth M, Forster CR, Illing RB (1997) Postnatal development of GAP-43 immunoreactivity in the auditory brainstem of the rat. J Comp Neurol 382:104-115.

Hoskins SG (1986) Control of the development of the ipsilateral retinothalamic projection in Xenopus laevis by thyroxine: results and speculation. J Neurobiol 17:203-229.

- Illing RB, Cao QL, Forster CR, Laszig R (1999) Auditory brainstem: development and plasticity of GAP-43 mRNA expression in the rat. J Comp Neurol 412:353-372.

- Jacobson RD, Virág I, Skene JH (1986) A protein associated with axon growth, GAP-43, is widely distributed and developmentally regulated in rat CNS. J Neurosci 6:1843-1855.
Kollros JJ, Thiesse ML (1988) Control of tectal cell number during larval development in Rana pipiens. J Comp Neurol 278:430-445.

-Kumaresan V, Kang C, Simmons AM (1998) Development and differentiation of the anuran auditory brainstem across metamorphosis: An acetylcholinesterasehistochemical study. Brain Behav Evol 52:111-125.

-Marín O, González A, Smeets WJAJ (1997) Basal ganglia organization in amphibians: Efferent connections of the striatum and the nucleus accumbens. J Comp Neurol 380:2350.

McDiarmid RW, Altig R (1999) Research: materials and techniques. In: Tadpoles: the Biology of Anuran Larvae (McDiarmid RW, Altig R, eds), pp 7-23. Chicago, IL: University of Chicago Press.

McGuire CB, Snipes GJ, Norden JJ (1988) Lightmicroscopic immunolocalization of the growth- and plasticity-associated protein GAP-43 in the developing rat brain. Dev Brain Res 41:277-291.

Meiri KF, Pfenninger KH, Willard MB (1986) Growth-associated protein, GAP-43, a polypeptide that is induced when neurons extend axons, is a component of growth cones and corresponds to $\mathrm{pp} 46$, a major polypeptide of a subcellular fraction enriched in growth cones. Proc Natl Acad Sci USA 83:35373541.

Neve RL, Finch EA, Bird ED, Benowitz LI (1988) Growth-associated protein GAP-43 is expressed selectively in associative regions of the adult human brain. Proc Natl Acad Sci USA 85:3638-3642.

Nieuwenhuys R, Opdam P (1976) Structure of the brain stem. In: Frog Neurobiology (Llinas R, Precht W, eds), pp 81-855. New York: Springer-Verlag.

Northcutt RG, Ronan M (1992) Afferent and efferent connections of the bullfrog medial pallium. Brain Behav Evol 40:1-16.

-Oestreicher AB, Gispen WH (1986) Comparison of the immunocytochemical distribution of the phosphoprotein B-50 in the cerebellum and hippocampus of immature and adult rat brain. Brain Res 375:267-279.

-Oestreicher AB, De Graan PN, Gispen WH, Verhaagen J, Schrama LH (1997) B-50, the growth associated protein-43: modulation of cell morphology and communication in the nervous system. Prog Neurobiol 53:627686.

Opdam R, Kemali M, Nieuwenhuys R (1976) Topological analysis of the brain stem of the frogs Rana esculenta and Rana catesbeiana. J Comp Neurol 165:307-332.

-Reh TA, Constantine-Paton M (1984) Retinal ganglion cell terminals change their projection sites during larval development of Rana pipiens. J Neurosci 4:442-457.

- Roden K, Endepols H, Walkowiak W (2005) Hodological characterization of the septum in anuran amphibians: I. Afferent connections. J Comp Neurol 483:415-436.
Rodger J, Bartlett CA, Harman AM, Thomas C, Beazley LD, Dunlop SA (2001) Evidence that regenerating optic axons maintain longterm growth in the lizard Ctenophorus ornatus: growth-associated protein-43 and gefiltin expression. Neuroscience 102:647-654.

-Schrama LH, Lepperdinger G, Moritz A, van den Engel NK, Marquart A, Oestreicher AB, Eggen BJ, Hage WJ, Richter K, Destree OH (1997) B-50/growth-associated protein-43, a marker of neural development in Xenopus laevis. Neuroscience 76:635-652.

Shi Y-B (1999) Amphibian Metamorphosis: From Morphology to Molecular Biology. New York: Wiley-Liss.

Simmons AM, Horowitz SS (2007) Plasticity in the auditory system across metamorphosis. In: Hearing and Sound Communication in Amphibians (Fay RR, Popper AN, Narins PM, Feng AS, eds), pp 291-322. New York: Springer-Verlag.

-Simmons AM, Chapman JA, Brown RA (2006) Developmental changes in cell proliferation in the auditory midbrain of the bullfrog, Rana catesbeiana. J Neurobiol 66:12121224.

- Simmons AM, Horowitz SS, Brown RA (2008) Cell proliferation in the midbrain and forebrain of the adult frog, Rana catesbeiana. Brain Behav Evol 71:41-53.

Skene JH (1989) Axonal growth-associated proteins. Ann Rev Neurosci 12:127-156.

-Skene JH, Willard M (1981) Changes in axonally transported proteins during axon regeneration in toad retinal ganglion cells. J Cell Biol 89:86-95.

Skene JH, Jacobson RD, Snipes GJ, McGuire CB, Norden JJ, Freeman JA (1986) A protein induced during nerve growth (GAP-43) is a major component of growth-cone membranes. Science 233:783-786.

Soto I, Marie B, Baro DJ, Blanco RE (2003) FGF2 modulates expression and distribution of GAP-43 in frog retinal ganglion cells after optic nerve injury. J Neurosci Res 73:507517.

-Van der Zee CE, Nielander HB, Vos JP, Lopes da Silva S, Verhaagen J, Oestreicher AB, Schrama LH, Schotman P, Gispen WH (1989) Expression of growth-associated protein B-50 (GAP43) in dorsal root ganglia and sciatic nerve during regenerative sprouting. J Neurosci 9:3505-3512.

-Westhoff G, Roth G, Straka H (2004) Topographic representation of vestibular and somatosensory signals in the anuran thalamus. Neuroscience 124:669-683.

-Wilczynski W, Northcutt RG (1983) Connections of the bullfrog striatum: Afferent organization. J Comp Neurol 214:321-332.

-Zakon HH, Capranica RR (1981) Reformation of organized connections in the auditory system after regeneration of the eighth nerve. Science 213:242-244. 